\title{
Extended Injection Intervals of Gonadotropins With Superficial Skin Administration In Ivf Treatment Is both Cost-Effective and Patient-Friendly
}

Isabel Hsu

Department of Obstetrics and Gynecology, National Taiwan University

\section{Leonard Hsu}

Nepean Blue Mountains Local Health District

Chao Chin Hsu ( $\nabla$ tube2363808@gmail.com )

University of Cambridge https://orcid.org/0000-0002-8082-1196

\section{Research}

Keywords: gonadotropins, longer interval, superficial subcutaneous administration, patient-friendly, cost-

effective

Posted Date: December 31st, 2020

DOl: https://doi.org/10.21203/rs.3.rs-136803/v1

License: (c) (1) This work is licensed under a Creative Commons Attribution 4.0 International License. Read Full License 


\section{Abstract}

Background

Women undergoing IVF treatments have to receive daily injections of $\mathrm{rFSH}$ for multiple follicles growth based on the short half-life of rFSH administered subcutaneously. This study was designed to assess if longer intervals of injection, based on rFSH half-life of 102 hours under superficial subcutaneous administration, effective for women receiving IVF.

Methods

One hundred women, aged 25-45, requesting IVF treatments from January to December 2018 were recruited in this observatory study. All women received long protocol employing $\mathrm{GnRH}$-agonist since day 18 of the previous cycle. An initial bolus of $900 \mathrm{IU} \mathrm{rFSH}$ was injected into superficial subcutaneous skin at day 2 of the treatment cycle followed by longer intervals with added doses at day 7 and/or day 10. The main outcomes included the dose of gonadotropin and numbers of injection, serum FSH level, and mature oocytes retrieved.

Results

A total of 70 women completed the treatments, in which 10, 30, and 30 women received one, two and three injections of $\mathrm{rFSH}$, respectively. On average, $2.31 \pm 0.73$ numbers of $\mathrm{Gn}$ injection and $1662 \pm 397 \mathrm{IU}$ of $\mathrm{rFSH}$ were administered. In comparison with baseline FSH level of $5.6 \pm 2.2 \mathrm{IU} / \mathrm{L}$, the serum concentrations of FSH were $35.3 \pm 7.0$ to $10.7 \pm 3.7 \mathrm{IU} / \mathrm{L}$ at 1 to 5 days after an initial $900 \mathrm{IU} \mathrm{rFSH}$ administration. There were 10.5 \pm 6.6 mature oocytes retrieved which resulted in $7.3 \pm 5.1$ two pronuclei embryos, and $1.8 \pm 0.6$ embryos were transferred back to the uterus and the remaining embryos were cryopreserved. In total, $72 \%, 91 \%$, and $31 \%$ were noted for fertilization, cleavage, and implantation rates, respectively. The cumulative live birth rate was $36 \%$.

Conclusions

Based on the serum FSH levels detected, $\mathrm{rFSH}$ only needs to be administered every five days instead of daily injection. This administration mode with less injections and much less expenses for gonadotropin might reach the goal of a more patient-friendly and cost-effective treatment for IVF. Regarding higher response and efficacy of the present study, this administration mode could be employed in women with poor ovarian reserve and in women of poor or suboptimal ovarian response.

Trial registration: None

\section{Background}

Controlled ovarian stimulation (COS), employing gonadotropin (Gn) administration, is the single most effective measure to increase the pregnancy rates of assisted reproduction (1). The efficacy of COS depends on both ovarian reserve and individual heterogeneity in ovarian response to gonadotropin $(2,3)$. 
Systematic review and meta-analysis indicated that high number $(>15)$ of oocytes retrieved were associated with more good quality embryos and more embryos frozen to achieve higher cumulative pregnancy rates (4-6). Those studies indicated that women receiving in vitro fertilization (IVF) treatments have to receive COS to enhance multiple follicle growth to achieve better outcomes. The situation has changed over the last decade, a shift from 'the more oocytes, the better' towards an optimal range of retrieved oocytes to maximize the chances of conceiving $(7,8)$. The standard, heavy-handed stimulation protocols will give way to simpler personalized infertility treatment (9). Thus, a more patient-friendly approach including the administration mode of $\mathrm{G} n$ is becoming a popular trend.

According to follicle-stimulating hormone (FSH) threshold theory (10), a certain level of FSH should be exceeded to enhance the FSH-dependent preantral and early antral follicles progress to maturation (11). Conventional pharmacokinetic study showed the terminal half-life $\left(\mathrm{t}_{1 / 2}\right)$ of recombinant $\mathrm{FSH}(\mathrm{rFSH})$ was only $17 \pm 4$ hours (12). Thus, it is an universal belief that daily administration of $\mathrm{Gn}$ to maintain adequate serum FSH concentration is the most important single factor for COS (13). Nowadays, many women in developed countries are injecting $\mathrm{Gn}$ by themselves for COS using the self-injecting pen which contains rFSH and/or recombinant luteinizing hormone (rLH). However, daily injection of $\mathrm{Gn}$ is very stressful especially for women of developing and under-developed countries.

Studies have suggested that the skin is a natural time-release system, with medicine injected into superficial subcutaneous and/or dermal layers remaining in the injected area longer as it is cleared more slowly by the general circulation than medicine injected more deeply $(14,15)$. We have demonstrated that superficial subcutaneous administration of $\mathrm{rFSH}$ lead to an extended absorption by higher area under the plasma concentration time graph $\left(\mathrm{AUC}_{0-\infty}\right)$, lower elimination rate constant, and slower total body clearance (16, 17). A highly increased net absorption ( $A \cup C_{0-\infty} 1,915.7 \mathrm{IU} * \mathrm{~h} / \mathrm{L}$ and $t_{1 / 2} 101.8 \mathrm{~h}$ ) employing this administration mode, compared with that $\left(\mathrm{AUC}_{0-\infty} 1,134 \mathrm{IU} * \mathrm{~h} / \mathrm{L}\right.$ and $\left.\mathrm{t}_{1 / 2} 46 \mathrm{~h}\right)$ of conventional subcutaneous injection of $\mathrm{rFSH}$ was found. The terminal half-life of 102 hours for $\mathrm{rFSH}$ indicated a mechanism of which depot-like effect could be reached and $\mathrm{Gn}$ administered was slowly released or absorbed (17). Thus, rFSH could be administered at a longer interval instead of daily injection to maintain adequate serum concentration for multiple follicular growth.

This study analyzed the effectiveness of superficial subcutaneous administration of $\mathrm{G} n$ in women receiving IVF. The results of this study raised another scenario for COS in which far less injections and doses of $\mathrm{Gn}$ were required to complete the COS process.

\section{Methods}

\section{Study Population and Design}

Women experiencing infertility requesting IVF treatments from January to December 2018 were approached. The initial plan was to recruit 100 participants for the study. The inclusion criteria were infertile women aged 25-45 years, body mass index (BMI) $17.0-28.0 \mathrm{~kg} / \mathrm{m} 2$, presence of bilateral ovaries, and early follicular phase FSH serum concentration of 1-15 IU/L. The main exclusion criteria were endometriosis stage III-IV, 
history of recurrent miscarriage, unexplained infertility, and use of hormonal preparations during the last 3 menstrual cycles and those for preimplantation genetic screening (PGS) and preimplantation genetic diagnosis (PGD).

\section{Controlled Ovarian Stimulation}

Long protocol was applied and participants received oral pills (Marvelon, containing $0.03 \mathrm{mg}$ ethinyl oestradiol and $0.15 \mathrm{mg}$ desogestrel, NV Organon, Oss, The Netherlands), starting at day 3 of the precedent cycle. From day 18, gonadotropin releasing hormone-agonist (GnRH-agonist) nasal spray (200 mg Buserelin acetate, Aventis Pharma Deutschland GMBH, Frankfurt, Germany) was given three times daily to achieve pituitary suppression. The $\mathrm{GnRH}$-agonist was maintained throughout $\mathrm{COS}$ to the day of human chorionic gonadotropin (hCG) triggering. Gonadotropin (900 IU rFSH; Gonal-f, Merck Serono S.p.A., Modugno, Italy) was initiated on day 2 of the IVF cycle once pituitary suppression was achieved as manifested by serum estradiol (E2) $<50 \mathrm{pg} / \mathrm{mL}$, LH $<2.5 \mathrm{mlU} / \mathrm{mL}$, and $\mathrm{FSH}<10 \mathrm{mlU} / \mathrm{mL}$. The injection of $\mathrm{Gn}$ was in accordance with our established method. In brief, the content of rFSH was aspirated into a $2.5 \mathrm{~mL}$ syringe adapted with a 30 gauge needle and injected into superficial subcutaneous skin of the lower abdominal wall (17). The follicular growth was detected by 2D ultrasound scanning (Aloka 900, Tokyo, Japan). The serum FSH and E2 were followed daily for 6 days and in some women till maturation of follicles. Women attended the clinic on day 2 and 7 of their menstrual cycle for the administration of $\mathrm{rFSH}$ and ultrasound scanning. At day 7 , if follicular growth did not reach the criteria ( 2 or more follicles $\geq 17 \mathrm{~mm}$ ) for the egg retrieval, a second dose rFSH injection was administered. The dosage for the second rFSH injection was based on the follicles detected, $450 \mathrm{IU} \mathrm{rFSH}$ used if $\geq 2$ follicles larger than $12 \mathrm{~mm}, 600 \mathrm{IU} \mathrm{rFSH}$ used if most follicles $\leq 12 \mathrm{~mm}$. The maturation of follicles would be followed at day 10 , and the third dose or further injections of Gn would be given if the maturation of follicles was not reached (Figure 1).

\section{Oocyte Retrieval and Clinical Outcomes}

The procedures of egg retrieval were performed in accordance with our established methods. In brief, oocyte retrieval took place 36 hours after triggering of final follicular maturation using hCG 10,000 IU (N.V. Organon, Oss, The Netherlands) when two or more follicles reached $\geq 17 \mathrm{~mm}$ in diameter. The mature oocytes obtained were fertilized in vitro or by intracytoplasmic sperm injection (ICSI). The immature oocytes were cultured for 24 hours and then fertilized if mature. Fertilized pre-embryos were cultured to day 3 cleavage stage embryos for embryo transfer. The number of embryos transferred was based on the age of women, in which single embryo, two, and three embryos were transferred in those $\leq 35,35$ to 40 ; and $\geq 40$ years-old, respectively. Surplus embryos were cryopreserved at day 3 cleavage stage or blastocyst stage. Micronized progesterone (utrogesterone, Besins Healthcare, Ayutthaya, Thailand) $100 \mathrm{mg}$ three times daily was used for luteal support from the day after oocyte retrieval for 15 days till the confirmation of pregnancy by serum hCG determination. Clinical pregnancy was confirmed by ultrasound scanning performed at 4 weeks after embryo transfer. The safety endpoints included the proportion of women with moderate/severe grade ovarian hyperstimulation syndrome (OHSS) and preventive interventions for early OHSS (i.e., cycle cancellation due to excessive ovarian response). Adverse responses such as pain sensation during $\mathrm{Gn}$ injection and skin responses were also recorded. 


\section{Study Outcome Measures}

The main outcomes included the dose of gonadotropin used and numbers of injection, serum FSH and E2 levels and targeted ovarian response (follicular growth, mature oocytes retrieved). The co-primary outcomes were fertilization, implantation, clinical pregnancy, and live birth rates. The dynamical aspect of the follicular response to COS including ovarian sensitivity index (OSI: the total dose of Gn used divided by number of mature oocytes obtained) (18), follicular output rate (FORT: the ratio of pre-ovulatory follicle (14-22 $\mathrm{mm}$ in diameter) count on hCG day $\times 100 /$ small antral follicle (3-8 $\mathrm{mm}$ in diameter) count at baseline.) (19), and follicle to oocyte index (FOI: the ratio between the number of oocytes obtained and the number of antral follicles at the beginning of COS) (20) were analyzed.

\section{Measurement of serum hormone levels}

The Beckman Coulter ACCESS immunoassay system was used in hormone assay (UniCelDxl 800, Beckman Coulter, Brea, CA). FSH and LH were measured in serum using a sequential two-step immunoenzymatic "sandwich" assay. The lowest detectable levels were $0.2 \mathrm{IU} / \mathrm{L}$ and the assay exhibits total imprecision of $\leq$ $10 \%$ for both FSH and LH. AMH levels were measured in serum samples using a simultaneous 1-step immunoenzymatic ("sandwich") assay. The assay has a limit of detection of $\leq 0.02 \mathrm{ng} / \mathrm{mL}$, with total imprecision $\leq 10.0 \%$ at concentrations $\geq 0.16 \mathrm{ng} / \mathrm{mL}$. The competitive binding immunoenzymatic assay was used for estradiol and progesterone serum level analysis. The lowest detectable level of estradiol is 20 $\mathrm{pg} / \mathrm{mL}$, and of progesterone is $0.10 \mathrm{ng} / \mathrm{mL}$.

\section{Statistical Analysis}

Continuous variables were described by mean and standard deviation (mean \pm SD). To compare means between groups, one-way ANOVA nonparametric Wilcoxon Mann- Whitney tests were used. A Chi-Square test was used for the categorical distributions. JMP Statistics v22.0 software was used for statistical analyses. $P<0.05$ was considered statistically significant.

\section{Results}

Among 100 women approached, 30 women were excluded. Seventy participants were enrolled to receive the new mode of $\mathrm{Gn}$ administration (Fig. 1). Their average age was $33.5 \pm 3.6$ years-old, and BMI was $21.3 \pm 2.5$ $\mathrm{Kg} / \mathrm{M}^{2}$. Their average serum AMH level was $3.5 \pm 2.6 \mathrm{ng} / \mathrm{mL}$ and duration of infertility was $5.0 \pm 3.0$ years (Table 1). Primary infertility was found in 52 women. The causative factors of infertility included 4 women of ovulatory dysfunction, 12 polycystic ovarian syndrome (PCOS), 22 tubal, 14 endometriosis, 15 adenomyosis, 10 myoma, 26 pelvic adhesion, 19 male factor, and 3 other uterine factors; with some participants having multiple factors. 
Table 1

Demographic patterns of participants with different doses of $\mathrm{Gn}$ administered

\begin{tabular}{|c|c|c|c|c|c|c|c|c|}
\hline $\begin{array}{l}\text { (Number of } \\
\text { subjects) }\end{array}$ & $\begin{array}{l}\text { Total } \\
(70)\end{array}$ & $\begin{array}{l}P \\
\text { value } \\
\text { among } \\
\text { three } \\
\text { groups }\end{array}$ & $\begin{array}{l}\begin{array}{l}\text { One } \\
\text { dose Gn } \\
\text { (Group A }\end{array} \\
10 \\
\text { subjects) }\end{array}$ & $\begin{array}{l}\text { Two } \\
\text { doses } \\
\text { Gn } \\
\text { (Group B } \\
30 \\
\text { subjects) }\end{array}$ & $\begin{array}{l}\text { Three } \\
\text { doses } \\
\text { Gn } \\
\text { (Group C } \\
30 \\
\text { subjects) }\end{array}$ & $\begin{array}{l}P \\
\text { value } \\
\text { Group } \\
\text { A } \\
\text { versus } \\
\text { Group } \\
\text { B }\end{array}$ & $\begin{array}{l}P \\
\text { value } \\
\text { Group } \\
\text { A } \\
\text { versus } \\
\text { Group } \\
\text { C }\end{array}$ & $\begin{array}{l}P \\
\text { value } \\
\text { Group } \\
\text { B } \\
\text { versus } \\
\text { Group } \\
\text { C }\end{array}$ \\
\hline Age & $\begin{array}{l}33.5 \\
\pm 3.6\end{array}$ & 0.194 & $\begin{array}{l}32.5 \pm \\
3.0\end{array}$ & $\begin{array}{l}33.0 \pm \\
3.7\end{array}$ & $\begin{array}{l}34.4 \pm \\
3.6\end{array}$ & 0.962 & 0.132 & 0.096 \\
\hline Years infertile & $\begin{array}{l}5.0 \pm \\
3.0\end{array}$ & 0.700 & $4.7 \pm 1.7$ & $4.8 \pm 3.1$ & $5.4 \pm 3.5$ & 0.498 & 0.735 & 0.710 \\
\hline $\begin{array}{l}\text { Primary } \\
\text { infertile (\%) }\end{array}$ & $75 \%$ & 0.226 & $90 \%$ & $66 \%$ & $80 \%$ & 0.087 & 0.471 & 0.150 \\
\hline $\begin{array}{l}\text { Previous IVFa } \\
(\%)\end{array}$ & $35 \%$ & 0.379 & $20 \%$ & $43 \%$ & $32 \%$ & 0.229 & 0.492 & 0.341 \\
\hline BW (Kg) & $\begin{array}{l}54.6 \\
\pm 7.3\end{array}$ & 0.143 & $\begin{array}{l}54.4 \pm \\
4.5\end{array}$ & $\begin{array}{l}52.8 \pm \\
5.7\end{array}$ & $\begin{array}{l}56.5 \pm \\
9.0\end{array}$ & 0.206 & 0.444 & 0.072 \\
\hline $\mathrm{BL}(\mathrm{cm})$ & $\begin{array}{l}160.1 \\
\pm 5.1\end{array}$ & 0.323 & $\begin{array}{l}158.9 \pm \\
4.9\end{array}$ & $\begin{array}{l}159.5 \pm \\
5.5\end{array}$ & $161 \pm 4.8$ & 0.730 & 0.198 & 0.230 \\
\hline $\mathrm{BMI}\left(\mathrm{Kg} / \mathrm{M}^{2}\right)$ & $\begin{array}{l}21.3 \\
\pm 2.5\end{array}$ & 0.250 & $\begin{array}{l}21.6 \pm \\
1.7\end{array}$ & $\begin{array}{l}20.7 \pm \\
1.9\end{array}$ & $\begin{array}{l}21.7 \pm \\
3.0\end{array}$ & 0.241 & 0.767 & 0.318 \\
\hline $\mathrm{AMH}(\mathrm{ng} / \mathrm{mL})$ & $\begin{array}{l}3.5 \pm \\
2.6\end{array}$ & 0.739 & $2.2 \pm 1.0$ & $4.1 \pm 3.2$ & $3.2 \pm 2.2$ & 0.502 & 0.690 & 0.584 \\
\hline $\begin{array}{l}\text { Antral follicle } \\
\text { count }\end{array}$ & $\begin{array}{l}10.4 \\
\pm 3.8\end{array}$ & 0.170 & $\begin{array}{l}10.8 \pm \\
4.6\end{array}$ & $\begin{array}{l}12.9 \pm \\
5.2\end{array}$ & $\begin{array}{l}10.5 \pm \\
4.2\end{array}$ & 0.259 & 0.826 & 0.072 \\
\hline $\mathrm{FSH}^{\mathrm{b}}(\mathrm{IU} / \mathrm{L})$ & $\begin{array}{l}5.6 \pm \\
2.2\end{array}$ & 0.752 & $5.5 \pm 1.9$ & $5.8 \pm 2.3$ & $5.4 \pm 2.1$ & 0.668 & 0.549 & 0.203 \\
\hline $\mathrm{LH}^{\mathrm{b}}(\mathrm{IU} / \mathrm{L})$ & $\begin{array}{l}1.6 \pm \\
1.3\end{array}$ & 0.234 & $1.7 \pm 0.8$ & $1.6 \pm 1.4$ & $1.4 \pm 1.4$ & 0.826 & 0.054 & 0.640 \\
\hline $\begin{array}{l}\text { Estradiol }^{\mathrm{b}} \\
(\mathrm{pg} / \mathrm{mL})\end{array}$ & $\begin{array}{l}14.7 \\
\pm 8.6\end{array}$ & 0.146 & $\begin{array}{l}20.5 \pm \\
13.7\end{array}$ & $\begin{array}{l}14.6 \pm \\
8.8\end{array}$ & $\begin{array}{l}12.9 \pm \\
4.9\end{array}$ & 0.159 & 0.071 & 0.319 \\
\hline $\begin{array}{l}\text { Progesterone } \\
(\mathrm{ng} / \mathrm{mL})\end{array}$ & $\begin{array}{l}0.5 \pm \\
0.4\end{array}$ & 0.274 & $0.5 \pm 0.3$ & $0.5 \pm 0.5$ & $0.6 \pm 0.3$ & 0.457 & 0.777 & 0.108 \\
\hline $\begin{array}{l}\text { Total Gn dose } \\
\text { used (IU) }\end{array}$ & $\begin{array}{l}1568 \\
\pm 395\end{array}$ & $<.0001$ & 900 & $\begin{array}{l}1417 \pm \\
156\end{array}$ & $\begin{array}{l}1941 \pm \\
193\end{array}$ & $<.0001$ & $<.0001$ & $<.0001$ \\
\hline \multicolumn{9}{|c|}{$\begin{array}{l}\text { Continuous data are presented as mean } \pm \text { standard deviation. Categorical data are presented as (\%). } \\
\text { One way-ANOVA Wilcoxon Mann-Whitney test was used for continuous data, and } \chi^{2} \text { test was used for } \\
\text { the categorical data. a: percentage of participants previously received IVF treatment, b: baseline serum } \\
\text { hormone profile after GnRH-agonist. }\end{array}$} \\
\hline
\end{tabular}


The average serum FSH level of $5.5 \pm 2.1 \mathrm{mIU} / \mathrm{mL}$, E2 $14.7 \pm 8.6 \mathrm{pg} / \mathrm{mL}, \mathrm{LH} 1.5 \pm 1.3 \mathrm{mIU} / \mathrm{mL}$, progesterone $0.5 \pm 0.4 \mathrm{ng} / \mathrm{mL}$, and antral follicle number of $10.3 \pm 3.8$ were noted after $\mathrm{GnRH}$-agonist down regulation. For $\mathrm{COS}$, these women received $2.31 \pm 0.73$ numbers of $\mathrm{Gn}$ injection and $1661.80 \pm 396.58 \mathrm{IU}$ of $\mathrm{Gn}$. The average duration of $\mathrm{Gn}$ exposure was $8.8 \pm 2.1$ days. These women were stratified into three groups according to numbers of $\mathrm{Gn}$ injection required to reach the maturation of ovarian follicles: group $A$ of 10 women only received a single dose of $900 \mathrm{IU} \mathrm{rFSH}$, group B of 30 women received two doses of $\mathrm{Gn}$ (in average $1417 \mathrm{IU}$ ) and group $\mathrm{C}$ of 30 women received three doses of $\mathrm{Gn}$ (in average $1941 \mathrm{IU}$ ). No woman received more than three doses of $\mathrm{Gn}$ injections for $\mathrm{COS}$. Elevated serum concentrations of FSH surpass baseline FSH level were noted 1 to 5 days post initial bolus of $900 \mathrm{IU}$ rFSH administration and no difference was noted among three groups of women (Fig. 2A). Lower serum estradiol levels were noted in group $\mathrm{C}$ compared to groups A and B women (Fig. 2B). Higher numbers of medium to larger sized follicles (14$16 \mathrm{~mm}$ and $>17 \mathrm{~mm}$ ) were noted in group $A$ compared to groups $\mathrm{B}$ and $\mathrm{C}$ women (Fig. $2 \mathrm{C}$ ). The numbers of small, medium and large follicles at the day of hCG among three groups were not different (Fig. 2D). No difference was noted on their baseline characteristics such as infertility years, body weight, BMI, numbers of antral follicle count, and baseline $\mathrm{FSH}$ and $\mathrm{AMH}$ levels regarding numbers of $\mathrm{Gn}$ injection among three groups of women (Table 1).

There were $10.5 \pm 6.6$ mature oocytes retrieved which resulted in $7.3 \pm 5.0$ two pronuclei embryos, among those $1.6 \pm 0.6$ embryos were freshly transferred and the remaining embryos were cryopreserved. No difference was found regarding the numbers of mature oocytes retrieved, fertilization or clinical pregnancy rates among the three groups. However, high FORT and OSI were noted in group C women who received three injections of $\mathrm{Gn}$. The implantation rate was much higher in group $A(65 \%)$ compared to groups $B$, and C (26.8\% and $22.1 \%)$ women, respectively. Thirty-three women conceived with clinical pregnancy rate of $47 \%$, and the live birth rate was $36 \%$ (Table 2 ). A slightly lower live birth was noted in group C women which reflected its higher miscarriage rate. 
Table 2

Laboratory and clinical outcomes in participants with different doses of $\mathrm{Gn}$ administered

\begin{tabular}{|c|c|c|c|c|c|c|c|c|}
\hline $\begin{array}{l}\text { (Number of } \\
\text { subjects) }\end{array}$ & $\begin{array}{l}\text { Total } \\
\text { (70) }\end{array}$ & $\begin{array}{l}P \text { value } \\
\text { among } \\
\text { three } \\
\text { groups }\end{array}$ & $\begin{array}{l}\begin{array}{l}\text { One } \\
\text { dose Gn } \\
\text { (Group A }\end{array} \\
10 \\
\text { subjects) }\end{array}$ & $\begin{array}{l}\text { Two } \\
\text { doses } \\
\text { Gn } \\
\text { (Group B } \\
30 \\
\text { subjects) }\end{array}$ & $\begin{array}{l}\text { Three } \\
\text { doses } \\
\text { Gn } \\
\text { (Group C } \\
30 \\
\text { subjects) }\end{array}$ & $\begin{array}{l}P \\
\text { value } \\
\text { Group } \\
\text { A } \\
\text { versus } \\
\text { Group } \\
\text { B }\end{array}$ & $\begin{array}{l}P \\
\text { value } \\
\text { Group } \\
\text { A } \\
\text { versus } \\
\text { Group } \\
\text { C }\end{array}$ & $\begin{array}{l}P \\
\text { value } \\
\text { Group } \\
\text { B } \\
\text { versus } \\
\text { Group } \\
\text { C }\end{array}$ \\
\hline Mature eggs & $\begin{array}{l}10.4 \pm \\
6.5\end{array}$ & 0.434 & $7.8 \pm 3.7$ & $\begin{array}{l}11.4 \pm \\
7.5\end{array}$ & $\begin{array}{l}10.2 \pm \\
5.9\end{array}$ & 0.199 & 0.316 & 0.689 \\
\hline $\begin{array}{l}\text { Immature } \\
\text { eggs }\end{array}$ & $\begin{array}{l}1.8 \pm \\
2.5\end{array}$ & 0.881 & $1.4 \pm 1.5$ & $1.8 \pm 2.4$ & $1.9 \pm 3.0$ & 0.987 & 0.909 & 0.748 \\
\hline $2 \mathrm{PN}$ & $\begin{array}{l}7.3 \pm \\
5.0\end{array}$ & 0.874 & $6.4 \pm 2.5$ & $8.3 \pm 6.5$ & $6.5 \pm 3.7$ & 0.683 & 0.925 & 0.651 \\
\hline $\begin{array}{l}\text { Good } \\
\text { embryos }\end{array}$ & $\begin{array}{l}4.8 \pm \\
4.2\end{array}$ & 0.266 & $4.3 \pm 2.5$ & $5.8 \pm 5.3$ & $4.0 \pm 3.3$ & 0.716 & 0.691 & 0.288 \\
\hline$E^{a}$ no. & $\begin{array}{l}1.6 \pm \\
0.6\end{array}$ & 0.429 & $1.8 \pm 0.6$ & $1.6 \pm 0.7$ & $1.5 \pm 0.6$ & 0.584 & 0.219 & 0.381 \\
\hline $\begin{array}{l}\text { Embryos } \\
\text { frozen }\end{array}$ & $\begin{array}{l}3.1 \pm \\
3.9\end{array}$ & 0.625 & $2.0 \pm 2.0$ & $3.7 \pm 5.3$ & $2.7 \pm 2.7$ & 0.506 & 0.969 & 0.381 \\
\hline $\begin{array}{l}\text { Fertilization } \\
\text { rate \% }\end{array}$ & $72 \pm 22$ & 0.183 & $85 \pm 21$ & $71 \pm 18$ & $70 \pm 26$ & 0.074 & 0.080 & 0.990 \\
\hline $\begin{array}{l}\text { Cleavage } \\
\text { rate } \%\end{array}$ & $91 \pm 19$ & 0.947 & $88 \pm 25$ & $93 \pm 15$ & $90 \pm 22$ & 0.869 & 0.720 & 0.860 \\
\hline $\begin{array}{l}\text { Implantation } \\
\text { rate \% }\end{array}$ & $31 \pm 38$ & $0.036^{\star}$ & $65 \pm 47$ & $27 \pm 38$ & $22 \pm 30$ & $0.025^{\star}$ & $0.014^{\star}$ & 0.840 \\
\hline FORT $^{\mathrm{b}} \%$ & $77 \pm 41$ & $0.017^{*}$ & $60 \pm 21$ & $67 \pm 29$ & $91 \pm 51$ & 0.584 & $0.015^{\star}$ & $0.020 *$ \\
\hline $\mathrm{OSI}^{\mathrm{C}}(\mathrm{IU})$ & $\begin{array}{l}215.3 \\
\pm 148.2\end{array}$ & $0.017^{\star}$ & $\begin{array}{l}138.7 \pm \\
59.8\end{array}$ & $\begin{array}{l}184.7 \pm \\
112.6\end{array}$ & $\begin{array}{l}271.5 \pm \\
179.5\end{array}$ & 0.341 & $0.008^{\star}$ & $0.041^{*}$ \\
\hline $\begin{array}{l}\mathrm{FOI}^{\mathrm{d}} \text { mature } \\
\text { eggs } \%\end{array}$ & $90 \pm 42$ & 0.221 & $75 \pm 31$ & $88 \pm 41$ & $97 \pm 45$ & 0.381 & 0.070 & 0.367 \\
\hline $\begin{array}{l}\text { FOI total } \\
\text { eggs \% }\end{array}$ & $\begin{array}{l}105 \pm \\
45\end{array}$ & 0.221 & $87 \pm 32$ & $102 \pm 43$ & $114 \pm 49$ & 0.398 & 0.074 & 0.340 \\
\hline
\end{tabular}

Continuous data are presented as mean \pm standard deviation. Categorical data are presented as $\%(n)$. One-way ANOVA Wilcoxon Mann- Whitney test was used for continuous data, and $\chi^{2}$ test was used for the categorical data. a: embryo transfer, b: follicular output rate: the ratio of pre-ovulatory follicle (14$22 \mathrm{~mm}$ in diameter) count on hCG day $\times 100 /$ small antral follicle $(3-8 \mathrm{~mm}$ in diameter) count at baseline, c: ovarian sensitivity index: the total dose of Gn used divided by number of mature oocytes obtained, $\mathrm{d}$ : follicle to oocyte index: the ratio between the number of oocytes obtained and the number of antral follicles at the beginning of COS, e: ovarian hyperstimulation syndrome; *: $P<0.05$ 


\begin{tabular}{|c|c|c|c|c|c|c|c|c|}
\hline $\begin{array}{l}\text { (Number of } \\
\text { subjects) }\end{array}$ & $\begin{array}{l}\text { Total } \\
(70)\end{array}$ & $\begin{array}{l}P \text { value } \\
\text { among } \\
\text { three } \\
\text { groups }\end{array}$ & $\begin{array}{l}\text { One } \\
\text { dose Gn } \\
\text { (Group A } \\
10 \\
\text { subjects) }\end{array}$ & $\begin{array}{l}\text { Two } \\
\text { doses } \\
\text { Gn } \\
\text { (Group B } \\
30 \\
\text { subjects) }\end{array}$ & $\begin{array}{l}\text { Three } \\
\text { doses } \\
\text { Gn } \\
\text { (Group C } \\
30 \\
\text { subjects) }\end{array}$ & $\begin{array}{l}P \\
\text { value } \\
\text { Group } \\
\text { A } \\
\text { versus } \\
\text { Group } \\
\text { B }\end{array}$ & $\begin{array}{l}P \\
\text { value } \\
\text { Group } \\
\text { A } \\
\text { versus } \\
\text { Group } \\
\text { C }\end{array}$ & $\begin{array}{l}P \\
\text { value } \\
\text { Group } \\
\text { B } \\
\text { versus } \\
\text { Group } \\
\text { C }\end{array}$ \\
\hline $\mathrm{OHSS}^{\mathrm{e}}$ & $\begin{array}{l}10 \% \\
(7 / 70)\end{array}$ & 0.660 & $\begin{array}{l}10 \% \\
(1 / 10)\end{array}$ & $\begin{array}{l}13.8 \% \\
(4 / 29)\end{array}$ & $\begin{array}{l}15 \% \\
(2 / 30)\end{array}$ & 0.757 & 0.729 & 0.365 \\
\hline $\begin{array}{l}\text { Cycle } \\
\text { pregnancy } \\
\text { rate \% }\end{array}$ & $\begin{array}{l}47.0 \% \\
(33 / 70)\end{array}$ & 0.796 & $\begin{array}{l}70.0 \% \\
(7 / 10)\end{array}$ & $\begin{array}{l}43.3 \% \\
(13 / 30)\end{array}$ & $\begin{array}{l}43.3 \% \\
(13 / 30)\end{array}$ & 0.567 & 0.845 & 0.592 \\
\hline $\begin{array}{l}\text { Fresh ET } \\
\text { pregnancy } \\
\text { rate \% }\end{array}$ & $\begin{array}{l}37.1 \% \\
(26 / 70)\end{array}$ & & $\begin{array}{l}70.0 \% \\
(7 / 10)\end{array}$ & $\begin{array}{l}30.0 \% \\
(9 / 30)\end{array}$ & $\begin{array}{l}33.3 \% \\
(10 / 30)\end{array}$ & & & \\
\hline $\begin{array}{l}\text { Frozen ET } \\
\text { pregnancy } \\
\text { rate \% }\end{array}$ & $\begin{array}{l}100.0 \% \\
(7 / 7)\end{array}$ & & - & $\begin{array}{l}100.0 \% \\
(4 / 4)\end{array}$ & $\begin{array}{l}100.0 \% \\
(3 / 3)\end{array}$ & & & \\
\hline $\begin{array}{l}\text { Miscarriage } \\
\text { rate \% }\end{array}$ & $\begin{array}{l}24.2 \% \\
(8 / 33)\end{array}$ & 0.086 & 0 & $\begin{array}{l}23.1 \% \\
(3 / 13)\end{array}$ & $\begin{array}{l}38.5 \% \\
(5 / 13)\end{array}$ & 0.1299 & $0.037 *$ & 0.247 \\
\hline $\begin{array}{l}\text { Live birth } \\
\text { rate } \%\end{array}$ & $\begin{array}{l}36.0 \% \\
(25 / 70)\end{array}$ & 0.123 & $\begin{array}{l}70.0 \% \\
(7 / 10)\end{array}$ & $\begin{array}{l}33.3 \% \\
(10 / 30)\end{array}$ & $\begin{array}{l}26.7 \% \\
(8 / 30)\end{array}$ & 0.097 & $0.042^{\star}$ & 0.592 \\
\hline \multicolumn{9}{|c|}{$\begin{array}{l}\text { Continuous data are presented as mean } \pm \text { standard deviation. Categorical data are presented as } \%(n) \text {. } \\
\text { One-way ANOVA Wilcoxon Mann- Whitney test was used for continuous data, and } \chi^{2} \text { test was used for } \\
\text { the categorical data. a: embryo transfer, b: follicular output rate: the ratio of pre-ovulatory follicle (14- } \\
22 \mathrm{~mm} \text { in diameter) count on hCG day } \times 100 / \text { small antral follicle }(3-8 \mathrm{~mm} \text { in diameter) count at } \\
\text { baseline, c: ovarian sensitivity index: the total dose of Gn used divided by number of mature oocytes } \\
\text { obtained, d: follicle to oocyte index: the ratio between the number of oocytes obtained and the number } \\
\text { of antral follicles at the beginning of COS, e: ovarian hyperstimulation syndrome; *: } P<0.05\end{array}$} \\
\hline
\end{tabular}

No cycle cancellation due to poor or excessive ovarian response was noted in this study. Seven women (10\%) presented the symptoms and signs of OHSS, in which 1, 4, and 2 women occurred in groups $A$, B, and $\mathrm{C}$, respectively. All women showing symptoms of OHSS belonged to PCOS. Most of these were mild to moderate OHSS and only one woman in group B required abdominal tapping to relieve the discomfort. Four women noted a reddish appearance of the skin and among them 3 women had an itching sensation after Gn administration.

\section{Discussion}

This study raised a novel approach to COS for women undergoing IVF. There is a trend of reducing dose/injections of gonadotropins for COS over the last two decades, with an improved patient compliance and lower chance of error during drug administration (21). Fine tuning of the Gn dose, in accordance with potential ovarian response in every single woman as the so-called personalized IVF treatment, has become a safer and more effective IVF practice $(22,23)$. Our work, with enhanced extent of absorption and longer plasma half-life of $\mathrm{rFSH}$, provides the pharmacokinetic basis for a longer interval of $\mathrm{Gn}$ injection instead of 
daily injections (17). The dose of Gn used in the present injection mode for IVF was lower than that of $3000 \mathrm{IU} \mathrm{rFSH}$ required using conventional daily injections $(24,25)$, with $45 \%$ of the expense saved on $\mathrm{Gn}$. For those only receiving a single injection of $900 \mathrm{IU} \mathrm{rFSH}, 70 \%$ of the expense for $\mathrm{Gn}$ was saved. Reducing the total dose of $\mathrm{Gn}$ administered greatly diminishes the cost of each cycle. Furthermore, much less injections for COS bodes well for the convenience and satisfaction and greatly reduced the emotional stress for infertile women. Our result fits the theme that any protocol used during IVF treatment should aim at optimizing a success in relation to safety, burden of treatment and cost (26). Under the threat of pandemic of COVID-19 across the globe since early 2020, most women would prefer a simplified treatment regimen such as the administration mode we raised in this study, which reduced the visits to IVF clinics (27). The major drawback of this observatory study is that only a small population was enrolled. In addition, the high implantation and clinical pregnancy rates $(65 \%$ and $70 \%)$ were noted in a small number of participants receiving only a single dose of $\mathrm{Gn}$ injection. This leads to a more optimistic interpretation of the result and therefore future larger studies are required to prove its effectiveness.

Studies indicated that exogenous supraphysiological concentration of rFSH in early follicular phase could recruit a whole clustered cohort of early antral follicles with reduced variability in follicle size, and high serum FSH level maintained by successive COS could increase the growth rate of these follicles $(25,28,29)$. It was noted that the day 3 basal serum FSH value of $7.8 \mathrm{IU} / \mathrm{L}$ in women with regular menstrual cycles represented the FSH threshold for ovarian follicle growth (30). A study from the same group later found that the serum FSH threshold was around $4.65 \mathrm{IU} / \mathrm{L}$ for single dominant follicle growth in normal reproductive stage women (31). In the present study, the elevated serum concentrations of FSH $35.3 \pm 7.0$ to $10.7 \pm$ $3.7 \mathrm{IU} / \mathrm{L}$ at 1 to 5 days post single bolus $900 \mathrm{IU}$ rFSH administration, might have surpassed the FSH threshold for ovarian multi-follicle growth. The persisted high serum FSH levels for 5 days further reconfirm our previous pharmacokinetic study on $\mathrm{rFSH}$, an extended absorption with longer terminal half-life employing the present administration mode $(16,17)$.

In this study, we were cautious about over dosage of Gn and the risk of OHSS after this mode of administration. The initial 900 IU rFSH used was based on previous IVF studies in which a daily dose of 150 to $450 \mathrm{IU}$ rFSH was used to reach proper follicular growth $(25,32)$. This single $900 \mathrm{IU} \mathrm{rFSH}$ injection leads to maturation of follicles at day seven in 10 out of 70 women. In the rest of the participants, second and/or third injections have been added and an average duration of 8.8 days of $\mathrm{Gn}$ exposure was noted in this study. There might exist a different follicle growth pattern in women under initial higher $\mathrm{Gn}$ dose as the maturation of follicles was faster than previous reports in which 13 days of $G$ n exposure was required (33). A randomized comparative study would be needed to determine if differences exist between the present injection mode compared to conventional COS, especially for these women who achieved follicular maturity following only 6 days of $\mathrm{rFSH}$ exposure. For these required more than two injections of $\mathrm{Gn}$, if a higher dosage of Gn (e.g. $900 \mathrm{IU}$ instead of 450-600 IU rFSH) was used as the second injection at day 7, most ovarian follicles could have reached maturation at day 12 (with interval of 5 days). Thus, if the dosage of Gn was properly adjusted for the second injection, most women might only receive one or two injections of $\mathrm{Gn}$ to complete the process of COS. Alternatively, if $1200 \mathrm{IU} \mathrm{rFSH}$ or higher dosage was used in selected participants for their initial bolus administration, many of them might reach maturation of follicles in a 
single rFSH injection. In our recent clinical observation, around $50 \%$ of women could reach maturation of follicles and complete their COS after a single bolus of $1200 \mathrm{IU}$ Gn administration (unpublished data).

Under this injection mode, we have previously indicated that the serum FSH level is persistently high with a terminal half-life of 248 hours (17). Therefore, we would suggest that the $\mathrm{Gn}$ administration interval could be extended to 10 days, with persisted higher serum FSH concentrations surpassing the FSH threshold for multi-follicle growth, if a higher initial dosage of $\mathrm{rFSH}$ was used. The serum concentrations of FSH administered by this administration mode were shown to be presented as an initial high concentration accompanied with a long tail of low serum level. This pattern is similar to the step-down FSH administration, which exerts a strong negative selection by allowing maturation and dominance solely to a few selected follicles (34), and may prevent the risk of OHSS. It will be very likely, under the safety of rFSH dosage and preventing the risk of OHSS, many women will need just a single injection of Gn for COS under this administration mode. The fixed dose of rFSH used in this study echos the consensus reached in a recent Delphi conference which included fixed FSH-dose, and the importance of therapy simplification and standardization to improve efficiency during COS (35).

This administration mode was shown to have both advantages of conventional and mild COS including sufficient numbers of oocytes retrieved and had surplus embryos for cryopreservation, high pregnancy and live birth rates in fewer cycles, low $\mathrm{Gn}$ dose and fewer injections required (36). Studies have shown that high total $\mathrm{Gn}$ dose used for COS might exert a negative impact on the endometrium and/or oocyte/embryo (3741), and an improvement in live birth rates were noted with lower total $\mathrm{Gn}$ doses used in a recent analysis of Society for Assisted Reproductive Technology (SART) Registry (42). A systemic review indicated that an increased $\mathrm{Gn}$ dose does not increase pregnancy rate (43). An idea of "less is more" was raised with the fact that for each additional $100 \mathrm{IU}$ of Gn usage, the likelihood of live birth decreased by $2 \%$ (44). Similarly, a very recent report demonstrated that for every $500 \mathrm{IU}$ increase in FSH dosing for COS, there was a 3\% decrease both in clinical pregnancy and live birth (45). Specifically, total Gn doses $<2,000$ IU were noted with $27 \%$ higher rate of live birth compared with a $\mathrm{Gn}$ dose $>5,000 \mathrm{IU}$ (42). Both studies showed unnecessary increase in total $\mathrm{Gn}$ used could decrease live birth rate $(42,45)$. In addition, supraphysiological estradiol level after higher dose of Gn used, may increase the growth hormone-binding protein in bio-neutralizing GH and diminishing the level of insulin-like growth factor, which played a role in synergism with FSH and the follicular metabolism in stimulated cycles (46). Although no difference in euploidy rates and live birth rates following the transfer of euploid embryos between cycles with higher and lower stimulation dosages were noted in a recent retrospective cohort study (47), it has been suspected that high dose of the FSH might lead to adverse effects on the oocyte through some sort of epigenetic impacts or the FSH dosing was a surrogate marker for some intrinsic deficiency in the oocyte quality (48). Our present result mirrors those publications in that lower total dose of Gn used has better pregnancy and live birth rates.

A depot effect of the present administration mode is similar to that of long-acting $\mathrm{Gn}$ corifollitropin alfa which has the terminal half-life of 65 hours and has been proved to maintain its effect for one week (49). For those receiving corifollitropin alfa for COS, most women still required a daily supplement of Gn for 3-5 days, at one week after the first dose of corifollitropin alfa. Employing corifollitropin alfa for IVF treatments, the injection numbers of Gn was 5.4 (50), and total injection numbers were 9.8 to 11.9 in young women for 
the oocyte donation program (51). In contrast, women only received 2.3 injections of rFSH in the present study. Furthermore, the serum concentrations of FSH, the main key for proper follicle growth, can be monitored daily following the administration of $\mathrm{rFSH}$ as shown in the present study and in previous pharmacokinetic study (17). While using corifollitropin alfa, the serum levels of active medicine cannot be identified to which the added $\mathrm{Gn}$ dose be adjusted accordingly in low response patients or in those at risk of hyperstimulation $(52,53)$.

The numbers of oocytes retrieved and live birth rates derived in this study were comparable to that of SART data from 2008-2010, with high live birth rate and lower OHSS risk in which 11-15 oocytes were retrieved (54). Our clinical pregnancy rate of $47 \%$ was comparable to previous study in which a cumulative pregnancy rate of $44 \%$ in 10-13 oocytes retrieved (55). The analysis of FORT/FOI/OSI from our data also indicated an efficient response of our participants to the present $\mathrm{Gn}$ administration. Previous study indicated an inverse correlation between OSI and AMH, the OSI was $365.2 \pm 321.4$ and $616.4 \pm 688.5 \mathrm{IU}$ in those with AMH 2.78.5 and $0.25-1.1 \mathrm{ng} / \mathrm{ml}$, respectively (24). The OSI of $215 \pm 148 \mathrm{IU}$ observed in the present study indicated that women might reach follicle maturation under less doses of $\mathrm{Gn}$. Study indicated that low FORT of $30 \%$ represented hypo-response, and FORT approaching $80 \%$ represented an adequate response in conventional COS (19). The FORT observed in the present study was $77 \%$ under much lower dosage of Gn used compared to conventional COS. Higher FORT has been correlated to higher clinical pregnancy rate in women receiving IVF (56), however, we found a lower pregnancy rate in our participants with high FORT. In the present study, the FOI was $90-100 \%$ compared to normal response of $50 \%$ for conventional COS (20), which indicated the much higher response in our participants and efficacy of this new administration mode. Thus, the present administration mode of Gn might provide a new scenario for women with poor or hypo-response to ovarian stimulation.

\section{Conclusions}

Based on the serum FSH level detected in our studies, the gonadotropins may be administered every five to ten days instead of daily injection. This extended administration intervals for $\mathrm{Gn}$, that proved to be effective in enhancing follicle growth, could greatly reduce the treatment burden of women receiving COS and reach the goal of a cost-effective and patient-friendly procedure. Regarding higher response and efficacy of COS in the present study, this administration mode could be employed in women with poor ovarian reserve and in women of poor or suboptimal ovarian response. Further application of this administration mode will be welcomed in developing and under-developed countries, where many women dare not injecting medicine by themselves. This injection mode for $\mathrm{rFSH}$ may also be welcomed in some extremely conservative countries and in some Islamic societies, where women might have different social norms in public spaces.

Further prospective larger studies are mandatory to analyze (1) which population need fewer Gn injections to complete the COS process, (2) which dose of Gn was proper for selected women to achieve maturation of follicles in just a single injection, (3) which parameters are relevant to successful conception and live birth, and (4) if this administration mode is also effective in women receiving GnRH antagonist or other COS protocols. The administration of $\mathrm{Gn}$ for the purpose of COS might be revolutionized then. 


\section{Abbreviations}

cos

controlled ovarian stimulation;

Gn

gonadotropin;

IVF

In vitro fertilization;

$\mathrm{FSH}$

Follicle-stimulating hormone;

$\mathrm{rFSH}$

recombinant Follicle-stimulating hormone;

$\mathrm{rLH}$

recombinant luteinizing hormone;

$t_{1 / 2}$

half-life;

$\mathrm{AUC}_{0-\infty}$

area under the plasma concentration time graph;

$\mathrm{BMI}$

body mass index;

PGS

preimplantation genetic screening;

PGD

preimplantation genetic diagnosis;

GnRH-agonist

gonadotropin releasing hormone- agonist

hCG

human chorionic gonadotropin;

E2

estradiol;

ICSI

intracytoplasmic sperm injection;

OHSS

ovarian hyperstimulation syndrome;

$\mathrm{AMH}$

Antimullerian hormone;

OSI

ovarian sensitivity index;

FORT

follicular output rate;

FOI 
follicle to oocyte index;

PCOS

polycystic ovarian syndrome;

SART

Society for Assisted Reproductive Technology;

IRB

Institutional Review Board

\section{Declarations}

Ethics approval and consent to participate: The study was performed in accordance with the Declaration of Helsinki Good Clinical Practice and local regulatory requirements. All participants enrolled signed the informed consent to participate the study. This investigation was approved by the Institutional Review Board (TSMH IRB/Protocol No: 18-115-B).

Consent for publication: All participants enrolled in this study signed the informed consent for publication.

Availability of data and materials: The dataset used in this article will be shared on reasonable request to the corresponding author.

Competing interests: Nothing to declare.

Funding: Nothing to declare.

\section{Authors' contributions:}

Chao Chin Hsu: participation in study design, execution, analysis, manuscript drafting and critical discussion

Isabel Hsu: participation in study design, analysis, manuscript drafting and critical discussion

Leonard Hsu: participation in study design, analysis, manuscript drafting and critical discussion

All authors read and approved the final manuscript and agree to be personally accountable for their contributions.

Acknowledgements: Nothing to declare.

\section{References}

1. Pirtea P, de Ziegler D, Poulain M, Ayoubi JM. New Twists in Ovarian Stimulation and Their Practical Implications. Frontiers in medicine. 2019;6:197.

2. Fauser BC, Diedrich K, Devroey P. Predictors of ovarian response: progress towards individualized treatment in ovulation induction and ovarian stimulation. Human reproduction update. 2008;14(1):1-14. 
3. Nyboe Andersen A, Nelson SM, Fauser BC, García-Velasco JA, Klein BM, Arce JC. Individualized versus conventional ovarian stimulation for in vitro fertilization: a multicenter, randomized, controlled, assessor-blinded, phase 3 noninferiority trial. Fertil Steril. 2017;107(2):387-96.e4.

4. Drakopoulos P, Blockeel C, Stoop D, Camus M, de Vos M, Tournaye H, et al. Conventional ovarian stimulation and single embryo transfer for IVF/ICSI. How many oocytes do we need to maximize cumulative live birth rates after utilization of all fresh and frozen embryos? Human reproduction (Oxford, England). 2016;31(2):370-6.

5. Vermey BG, Chua SJ, Zafarmand MH, Wang R, Longobardi S, Cottell E, et al. Is there an association between oocyte number and embryo quality? A systematic review and meta-analysis. Reproductive biomedicine online. 2019;39(5):751-63.

6. Baker VL, Brown MB, Luke B, Conrad KP. Association of number of retrieved oocytes with live birth rate and birth weight: an analysis of 231,815 cycles of in vitro fertilization. Fertil Steril. 2015;103(4):9318.e2.

7. van der Gaast MH, Eijkemans MJ, van der Net JB, de Boer EJ, Burger CW, van Leeuwen FE, et al. Optimum number of oocytes for a successful first IVF treatment cycle. Reproductive biomedicine online. 2006;13(4):476-80.

8. Sunkara SK, Rittenberg V, Raine-Fenning N, Bhattacharya S, Zamora J, Coomarasamy A. Association between the number of eggs and live birth in IVF treatment: an analysis of 400135 treatment cycles. Human reproduction (Oxford, England). 2011;26(7):1768-74.

9. Paulson RJ. Introduction: Contemporary approaches to alternative ovarian stimulation strategies for in vitro fertilization. Fertil Steril. 2017;108(4):555-7.

10. Brown JB. Pituitary control of ovarian function-concepts derived from gonadotrophin therapy. The Australian \& New Zealand journal of obstetrics \& gynaecology. 1978;18(1):46-54.

11. van Santbrink EJ, Hop WC, van Dessel TJ, de Jong FH, Fauser BC. Decremental follicle-stimulating hormone and dominant follicle development during the normal menstrual cycle. Fertil Steril. 1995;64(1):37-43.

12. le Cotonnec JY, Porchet HC, Beltrami V, Khan A, Toon S, Rowland M. Clinical pharmacology of recombinant human follicle-stimulating hormone (FSH). I. Comparative pharmacokinetics with urinary human FSH. Fertil Steril. 1994;61(4):669-78.

13. Ben-Rafael Z, Levy T, Schoemaker J. Pharmacokinetics of follicle-stimulating hormone: clinical significance. Fertil Steril. 1995;63(4):689-700.

14. Kaplan R. Devenir d'un produit marque injecte par quatre voies differentes. Bulletin SFM (la Societe Francaise de Mesotherapie). 1985;62.

15. Le Coz J. Traité de mésothérapie: (DEPRECIATED); 2009.

16. Hsu CC, Kuo HC, Hsu CT, Gu Q. The absorption and uptake of recombinant human follicle-stimulating hormone through vaginal subcutaneous injections-a pharmacokinetic study. Reproductive biology and endocrinology : RB\&E. 2009;7:107.

17. Hsu CC, Kuo HC, Hsu CT, Gu Q. Abdominal mesotherapy injection extended the absorption of folliclestimulating hormone. Fertil Steril. 2011;95(6):2134-6, 6.e1. 
18. Biasoni V, Patriarca A, Dalmasso P, Bertagna A, Manieri C, Benedetto C, et al. Ovarian sensitivity index is strongly related to circulating $\mathrm{AMH}$ and may be used to predict ovarian response to exogenous gonadotropins in IVF. Reproductive biology and endocrinology : RB\&E. 2011;9:112.

19. Gallot V, Berwanger da Silva AL, Genro V, Grynberg M, Frydman N, Fanchin R. Antral follicle responsiveness to follicle-stimulating hormone administration assessed by the Follicular Output RaTe (FORT) may predict in vitro fertilization-embryo transfer outcome. Human reproduction (Oxford, England). 2012;27(4):1066-72.

20. Alviggi C, Conforti A, Esteves SC, Vallone R, Venturella R, Staiano S, et al. Understanding Ovarian HypoResponse to Exogenous Gonadotropin in Ovarian Stimulation and Its New Proposed Marker-The Follicle-To-Oocyte (FOI) Index. Frontiers in endocrinology. 2018;9:589.

21. Richter A, Anton SF, Koch P, Dennett SL. The impact of reducing dose frequency on health outcomes. Clinical therapeutics. 2003;25(8):2307-35; discussion 6.

22. La Marca A, Sunkara SK. Individualization of controlled ovarian stimulation in IVF using ovarian reserve markers: from theory to practice. Human reproduction update. 2014;20(1):124-40.

23. Datta AK, Maheshwari A, Felix N, Campbell S, Nargund G. Mild versus conventional ovarian stimulation for IVF in poor, normal and hyper-responders: a systematic review and meta-analysis. Human reproduction update. 2020.

24. Yadav V, Malhotra N, Mahey R, Singh N, Kriplani A. Ovarian Sensitivity Index (OSI): Validating the Use of a Marker for Ovarian Responsiveness in IVF. Journal of reproduction \& infertility. 2019;20(2):83-8.

25. Lolis DE, Tsolas O, Messinis IE. The follicle-stimulating hormone threshold level for follicle maturation in superovulated cycles. Fertil Steril. 1995;63(6):1272-7.

26. Nargund G, Fauser B. Mild ovarian stimulation for IVF is the smartest way forward. Reproductive biomedicine online. 2020;41(4):569-71.

27. Robertson I, Chmiel F, Cheong Y. Streamlining follicular monitoring during controlled ovarian stimulation: a data-driven approach to efficient IVF care in the new era of social distancing. Human reproduction (Oxford, England). 2020.

28. Abbara A, Vuong LN, Ho VNA, Clarke SA, Jeffers L, Comninos AN, et al. Follicle Size on Day of Trigger Most Likely to Yield a Mature Oocyte. Frontiers in endocrinology. 2018;9:193.

29. Abbara A, Patel A, Hunjan T, Clarke SA, Chia G, Eng PC, et al. FSH Requirements for Follicle Growth During Controlled Ovarian Stimulation. Frontiers in endocrinology. 2019;10:579.

30. Schoemaker J, van Weissenbruch MM, Scheele F, van der Meer M. The FSH threshold concept in clinical ovulation induction. Bailliere's clinical obstetrics and gynaecology. 1993;7(2):297-308.

31. de Koning $\mathrm{CH}$, Schoemaker J, Lambalk CB. Estimation of the follicle-stimulating hormone (FSH) threshold for initiating the final stages of follicular development in women with elevated FSH levels in the early follicular phase. Fertil Steril. 2004;82(3):650-3.

32. van Tilborg TC, Torrance HL, Oudshoorn SC, Eijkemans MJC, Koks CAM, Verhoeve HR, et al. Individualized versus standard FSH dosing in women starting IVF/ICSI: an RCT. Part 1: The predicted poor responder. Human reproduction (Oxford, England). 2017;32(12):2496-505. 
33. Humaidan P, Bungum L, Bungum M, Andersen CY. Ovarian response and pregnancy outcome related to mid-follicular LH levels in women undergoing assisted reproduction with $\mathrm{GnRH}$ agonist down-regulation and recombinant FSH stimulation. Human Reproduction. 2002;17(8):2016-21.

34. Navot D, Bergh P, Palermo R. Pathophysiology and clinical management of ovarian hyperstimulation. Ovulation induction: basic and clinical advances: Elsevier, Amsterdam; 1994. p. 319-29.

35. Bulletti C, Allegra A, Mignini Renzini M, Vaiarelli A. How fixed versus variable gonadotropin dose during controlled ovarian stimulation could influence the management of infertility patients undergoing IVF treatment: a national Delphi consensus. Gynecological Endocrinology. 2020:1-9.

36. Alper MM, Fauser BC. Ovarian stimulation protocols for IVF: is more better than less? Reproductive biomedicine online. 2017;34(4):345-53.

37. Baker VL, Brown MB, Luke B, Smith GW, Ireland JJ. Gonadotropin dose is negatively correlated with live birth rate: analysis of more than 650,000 assisted reproductive technology cycles. Fertil Steril. 2015;104(5):1145-52.e1-5.

38. Chen SU, Chou CH, Chen MJ, Chen TH, Yang YS, Yang JH. Apoptotic effects of high estradiol concentrations on endometrial glandular cells. The Journal of clinical endocrinology and metabolism. 2014;99(6):E971-80.

39. Horcajadas JA, Mínguez P, Dopazo J, Esteban FJ, Domínguez F, Giudice LC, et al. Controlled ovarian stimulation induces a functional genomic delay of the endometrium with potential clinical implications. The Journal of clinical endocrinology and metabolism. 2008;93(11):4500-10.

40. Sato A, Otsu E, Negishi H, Utsunomiya T, Arima T. Aberrant DNA methylation of imprinted loci in superovulated oocytes. Human reproduction (Oxford, England). 2007;22(1):26-35.

41. Market-Velker BA, Zhang L, Magri LS, Bonvissuto AC, Mann MR. Dual effects of superovulation: loss of maternal and paternal imprinted methylation in a dose-dependent manner. Human molecular genetics. 2010;19(1):36-51.

42. Kappy M, Gerber RS, Fazzari M, Galperin S, Cohen A, Lieman H, et al. HIGHER TOTAL GONADOTROPIN DOSE BUT NOT LENGTH OF STIMULATION IS INDEPENDENTLY ASSOCIATED WITH DECREASED LIVE BIRTH RATE IN FRESH IN VITRO FERTILIZATION-EMBRYO TRANSFER (IVF-ET) CYCLES: ANALYSIS OF 14,866 CYCLES FROM THE SART REGISTRY. Fertility and Sterility. 2020;113(4):e36-e7.

43. van Tilborg TC, Broekmans FJ, Dólleman M, Eijkemans MJ, Mol BW, Laven JS, et al. Individualized follicle-stimulating hormone dosing and in vitro fertilization outcome in agonist downregulated cycles: a systematic review. Acta obstetricia et gynecologica Scandinavica. 2016;95(12):1333-44.

44. Pal L, Jindal S, Witt BR, Santoro N. Less is more: increased gonadotropin use for ovarian stimulation adversely influences clinical pregnancy and live birth after in vitro fertilization. Fertil Steril. 2008;89(6):1694-701.

45. Shaia KL, Acharya KS, Harris BS, Weber JM, Truong T, Muasher SJ. Total follicle stimulating hormone dose is negatively correlated with live births in a donor/recipient model with fresh transfer: an analysis of 8,627 cycles from the Society for Assisted Reproductive Technology Registry. Fertil Steril. 2020.

46. Blumenfeld $Z$. Why more is less and less is more when it comes to ovarian stimulation. Journal of assisted reproduction and genetics. 2015;32(12):1713-9. 
47. Irani M, Canon C, Robles A, Maddy B, Gunnala V, Qin X, et al. No effect of ovarian stimulation and oocyte yield on euploidy and live birth rates: an analysis of 12298 trophectoderm biopsies. Human Reproduction. 2020;35(5):1082-9.

48. Franasiak JM. Follicle-stimulating hormone dosage negatively associated with live birth in donor/recipient model: a case for milder donor stimulation? Fertility and Sterility. 2020.

49. Duijkers IJ, Klipping C, Boerrigter PJ, Machielsen CS, De Bie JJ, Voortman G. Single dose pharmacokinetics and effects on follicular growth and serum hormones of a long-acting recombinant FSH preparation (FSH-CTP) in healthy pituitary-suppressed females. Human reproduction (Oxford, England). 2002;17(8):1987-93.

50. Croxtall JD, McKeage K. Corifollitropin alfa: a review of its use in controlled ovarian stimulation for assisted reproduction. BioDrugs : clinical immunotherapeutics, biopharmaceuticals and gene therapy. 2011;25(4):243-54.

51. Pérez-Calvo A, Martínez F, Blockeel C, Clúa E, Rodríguez I, Barri PN, et al. Importance of a 5- versus 7-day pill-free interval in a $\mathrm{GnRH}$ antagonist protocol using corifollitropin alfa: a prospective cohort study in oocyte donors. Reproductive biomedicine online. 2017;35(4):425-31.

52. Mahmoud Youssef MA, van Wely M, Aboulfoutouh I, El-Khyat W, van der Veen F, Al-Inany H. Is there a place for corifollitropin alfa in IVF/ICSI cycles? A systematic review and meta-analysis. Fertil Steril. 2012;97(4):876-85.

53. Fensore S, Di Marzio M, Tiboni GM. Corifollitropin alfa compared to daily FSH in controlled ovarian stimulation for in vitro fertilization: a meta-analysis. Journal of ovarian research. 2015;8:33.

54. Steward RG, Lan L, Shah AA, Yeh JS, Price TM, Goldfarb JM, et al. Oocyte number as a predictor for ovarian hyperstimulation syndrome and live birth: an analysis of 256,381 in vitro fertilization cycles. Fertility and sterility. 2014;101(4):967-73.

55. Fatemi HM, Doody K, Griesinger G, Witjes H, Mannaerts B. High ovarian response does not jeopardize ongoing pregnancy rates and increases cumulative pregnancy rates in a $\mathrm{GnRH}$-antagonist protocol. Human Reproduction. 2013;28(2):442-52.

56. Hassan A, Kotb M, AwadAllah A, Wahba A, Shehata N. Follicular output rate can predict clinical pregnancy in women with unexplained infertility undergoing IVF/ICSI: a prospective cohort study. Reproductive biomedicine online. 2017;34(6):598-604.

\section{Figures}




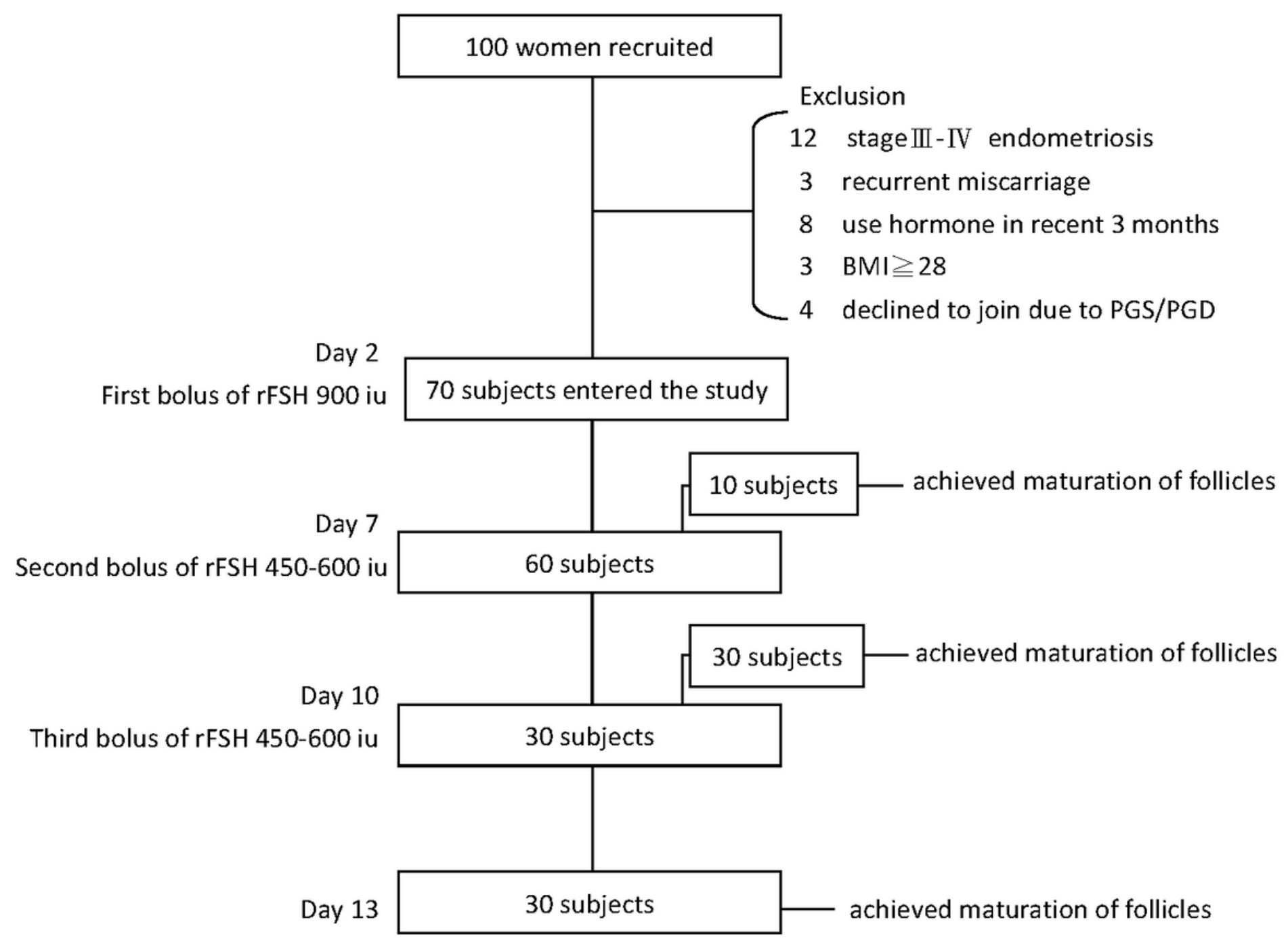

\section{Figure 1}

Consort chart showing the progress of the subjects through the study. 

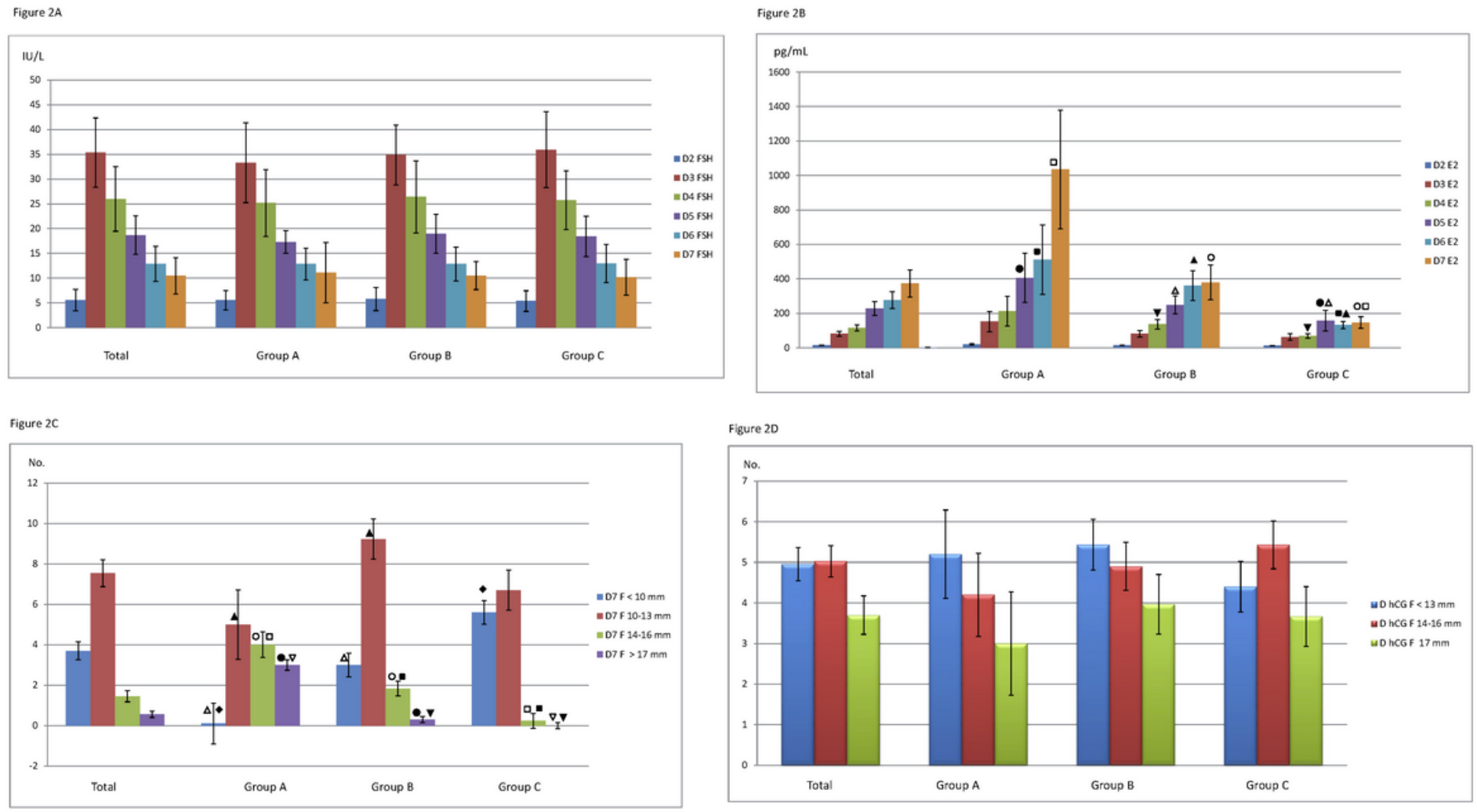

Figure 2

2A: The serum levels of FSH, from day 2 to day 7, in all subjects received single bolus of $900 \mathrm{IU} \mathrm{rFSH}$. In comparison of baseline FSH level of $5.61 \pm 2.21 \mathrm{IU} / \mathrm{L}$, elevated serum concentrations of FSH $(35.3 \pm 7.0$, $26.0 \pm 6.5,18.7 \pm 3.9,12.9 \pm 3.5$ to $10.71 \pm 3.71 \mathrm{IU} / \mathrm{L}$ ) were noted 1 to 5 days post initial bolus of $900 \mathrm{IU}$ rFSH administration. No difference in daily concentrations of serum FSH from days 2 to 7 after the first dose rFSH administration among three groups of subjects. 2B: The serum levels of E2, from day 2 to day 7 , in all subjects received single bolus of $900 \mathrm{IU} \mathrm{rFSH}$. No difference was found in daily concentrations of serum estradiol from days 2 to 7 between group A and group B. The serum levels of E2 in those received three doses of $\mathrm{rFSH}$ (group $\mathrm{C}$ ) were significantly lower than those received single or two doses of $\mathrm{rFSH}$ (groups A \& B). $\boldsymbol{\nabla} \square \triangle \mathbf{O}: \mathrm{P}<0.05, \square \mathbf{\Delta}: \mathrm{P}<0.005 .2 \mathrm{C}$ : Follicle growth at day 7 in all subjects received single bolus of $900 \mathrm{IU}$ rFSH. More large follicles and fewer small follicles were found in those only requiring a single dose rFSH (group A) compared to other groups women (groups B \& C). $\boldsymbol{\Delta} \boldsymbol{\nabla \nabla}: P<0.05, \triangle$ : $P<$ $0.005, \varangle \square \nabla \square: P<0.0001$. 2D: The size of follicles detected at the day of hCG triggering. The numbers of small $(\leq 13 \mathrm{~mm})$, medium $(14-16 \mathrm{~mm})$ and large follicles $(\geq 17 \mathrm{~mm})$ at the day of $h C G$ among three groups were not different. 